\title{
Erratum to: Metabolic syndrome and its predictors in an urban population in Kenya: a cross sectional study
}

Geoffrey Omuse ${ }^{1 *}$, Daniel Maina ${ }^{1}$, Mariza Hoffman², Jane Mwangi ${ }^{3}$, Caroline Wambua ${ }^{3}$, Elizabeth Kagotho ${ }^{1}$, Angela Amayo ${ }^{4}$, Peter Ojwang ${ }^{5}$, Zulfiqarali Premji ${ }^{6}$, Kiyoshi Ichihara ${ }^{7}$ and Rajiv Erasmus ${ }^{2}$

\section{Erratum}

The original article [1] was updated to correct a mistake in the third sentence of the conclusions section:

'There is also a need to adopt gender specific MetS TG cut-offs to avoid over diagnosing hypertriglyceridaemia in black African women who have a lower TG level compared to the $1.7 \mathrm{mmol} / \mathrm{L}$ cut-off.'

Has been changed to:

'There is also a need to adopt gender specific MetS TG cut-offs to avoid under diagnosing hypertriglyceridaemia in black African women who have a lower TG level compared to the $1.7 \mathrm{mmol} / \mathrm{L}$ cut-off.'

\section{Author details}

'Department of Pathology, Aga Khan University Hospital Nairobi, P.O. Box 30270-00100, Nairobi, Kenya. ${ }^{2}$ Division of Chemical Pathology, Department of Pathology, Stellenbosch University, Tygerberg Hospital, P.O. Box 19113, Cape Town, South Africa. ${ }^{3}$ PathCare Kenya Ltd, P.O. Box 12560-00606, Nairobi, Kenya. ${ }^{4}$ Department of Human Pathology, University of Nairobi, P.O. Box 19676-00200, Nairobi, Kenya. ${ }^{5}$ Department of Pathology, Maseno University, P.O. Box Private Bag, Maseno, Kenya. ${ }^{6}$ Formerly of Muhimbili University of Health and Allied Sciences, Dar es Salaam, Tanzania. ${ }^{7}$ Graduate School of Medicine, Faculty of Health Sciences, Yamaguchi University, Minami-Kogushi 1-1-1, Ube 755-8505, Japan.

Received: 10 July 2017 Accepted: 10 July 2017

Published online: 14 July 2017

\section{Reference}

1. Omuse G, Maina D, Hoffman M, Mwangi J, Wambua C, Kagotho E, Amayo A, Ojwang P, Premji Z, Ichihara K, Erasmus R. Metabolic syndrome and its predictors in an urban population in Kenya: a cross sectional study. BMC Endocr Disord. 2017;17:37. doi:10.1186/s12902-017-0188-0.

\footnotetext{
* Correspondence: 9_omuse@yahoo.com

'Department of Pathology, Aga Khan University Hospital Nairobi, P.O. Box 30270-00100, Nairobi, Kenya

Full list of author information is available at the end of the article
} 